\title{
Blunt Traumatic Diaphragmatic Hernia: Case Report
}

\author{
Siwipan Changtham, MD.
}

Department of Radiology, Buddachinnaraj Hospital, Muang, Phitsanulok, Thailand. 65000

\section{Case Report}

A 55-year old man visited the orthopedic OPD due to tenderness and swelling at left ankle from a motorcycle accident, 3 hours before. Left medial malleolus fracture was diagnosed. A short leg cast was performed by orthopedist. During the wait to receive his medicines, he had sudden onset of chest discomfort, pain at left lower chest and left upper abdomen. He was sent to the ER department. He had blood pressure of 110/75 mmHg, pulse rate of 64 beats/min, respiratory rate of 20 breaths/min and oxygen saturation of $97 \%$. A physical examination found mild pale conjunctiva, tender at left chest wall, equal breath sounds. Mild tenderness at LUQ was also noted without guarding or rebound tenderness

Chest film showed air-fluid level within left hemithorax and mild shifting of mediastinum to the right. A CT chest including upper abdomen with contrast study was performed. Discontinuity of left hemidiaphargm with herniation of stomach and duodenum into left hemithorax was seen. Splenic laceration and minimal left hemothorax were also noted.
He was admitted at the traumatic surgery ward for an exploratory laparotomy. Rupture of left hemidiaphragm, approximately $10 \mathrm{~cm}$ in diameter, with herniation of stomach, duodenum and omentum into left thorax was found. Left hemothorax and splenic contusion were also found. Repair to left diaphragm with interrupted non-absorptable sutures was performed. No evidence of complication was detected.

\section{Discussion}

Diaphragmatic hernia is a herniation of $a b-$ dominal structures into the thoracic cavity through a defect on the diaphragm. ${ }^{1}$ It can be broadly classified as acquired or congenital. ${ }^{2}$ Traumatic diaphragmatic hernia, acquired diaphragmatic hernia, is rare and often overlooked complication of penetrating and blunt trauma. ${ }^{3}$ It is present in $1-6 \%$ of major thoracic injuries. ${ }^{4}$ The common causes of traumatic diaphragmatic hernia are depending on the geographic location and socioeconomic status of trauma patients. $^{5}$

In blunt traumatic diaphragmatic rupture, motor vehicle accident is the most common cause, followed by falls and crush injuries. ${ }^{6-8}$ Mechanisms 


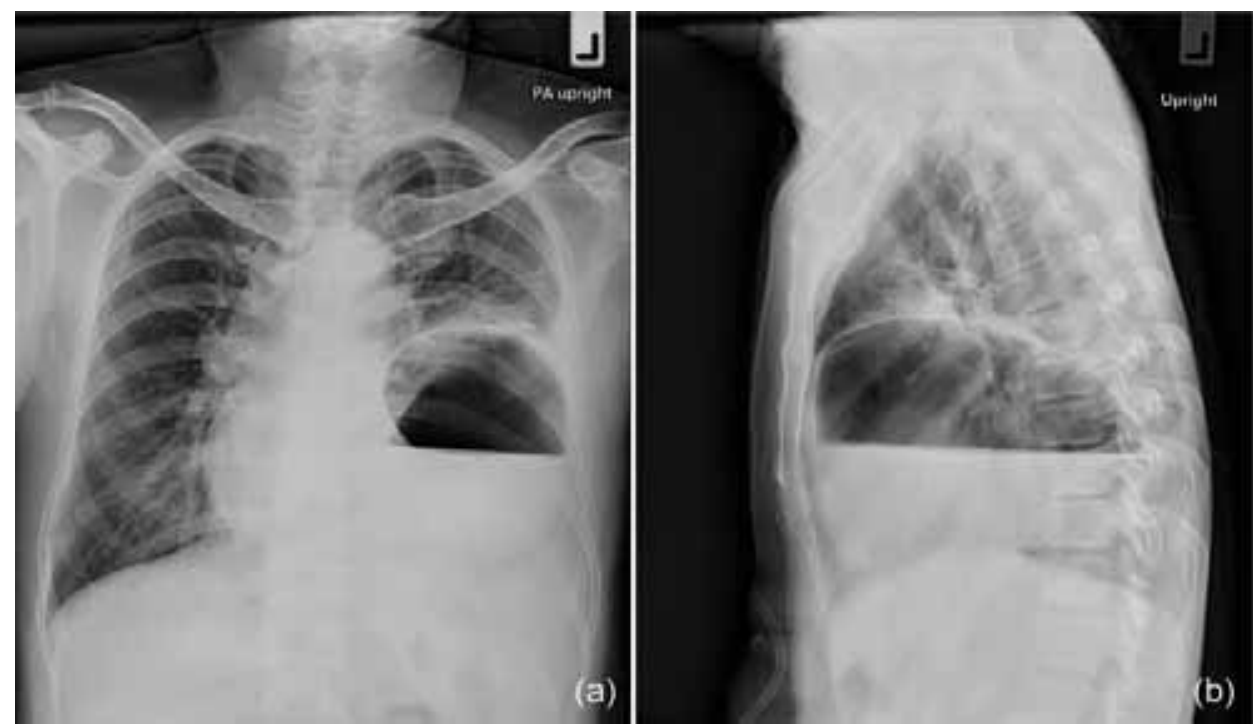

Fig 1. Chest radiographs in PA upright (a) and left lateral views (b) reveal air-fluid level within the left hemithorax. Mild shifting of the mediastinum to the right is noted.

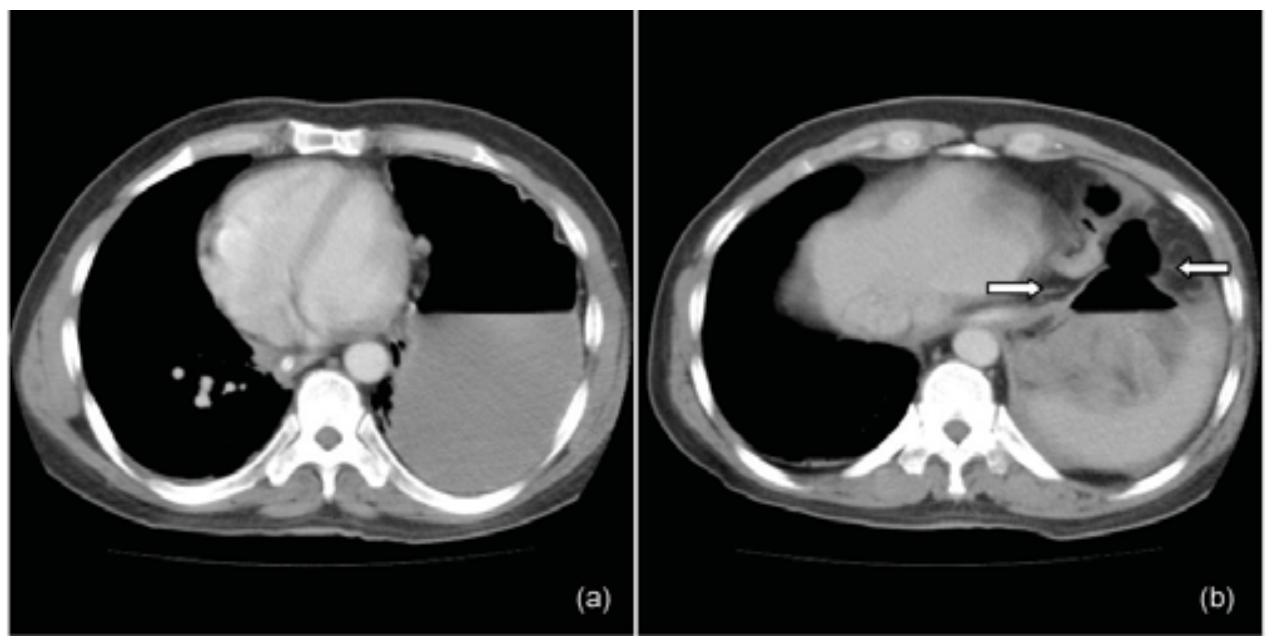

Fig 2. Axial contrast-enhanced CT images: (a) The stomach is in left hemithorax and in a dependent position. Contact of the stomach and the posterior thoracic wall is noted. (dependent viscera sign). (b) The waist like contraction of the stomach is seen at the level of left hemidiaphragm (The collar sign; white arrow).

of blunt diaphragmatic injury include a sudden increase in transdiaphragmatic pressure caused by direct frontal impact, distortion of the chest wall with resultant avulsion of the diaphragmatic attachments and direct penetration by rib fragments. ${ }^{9}$ The left-sided injury is significant predominantly, up to $95 \%$, while right-sided injury is less common from protective effect of liver. ${ }^{10-12}$
The stomach is the most common herniated organ in left-sided diaphragmatic rupture, followed by colon. ${ }^{13}$ The liver, kidney, spleen and small intestine may also migrate within thorax. ${ }^{1}$ The diaphragm is rarely injured alone, with an associated injury rate approaching $100 \%$, both intra-abdominal injuries and extra-abdominal injuries. ${ }^{14}$ Common intra-abdominal injuries are spleen and liver. ${ }^{8,13}$ Extra-abdominal 

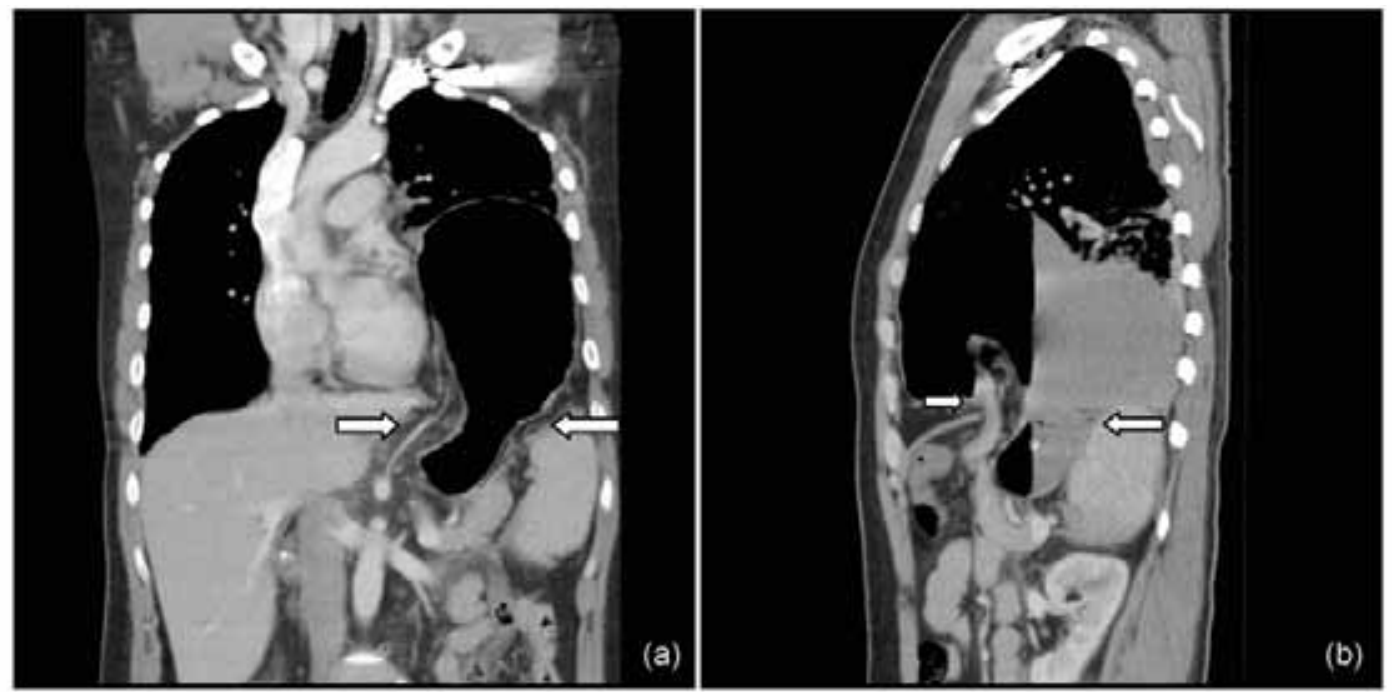

Fig.3 Contrast-enhanced CT images with coronal (a) and sagittal (b) show a focal defect of the left hemidiaphragm (segmental diaphragmatic defect sign; white arrow). Herniation of the stomach through this defect into left hemithorax is noted with the waist like contraction of the stomach at the level of diaphragm (The collar sign).

injuries are hemothorax, lung injury, fracture and head injury. $6,8,13$

Clinical presentation of diaphragmatic rupture was described in 3 phases. ${ }^{15}$ The acute phase is at the time of injury. Acute phase may be asymptomatic or present with chest pain, abdominal pain, respiratory distress or shock. ${ }^{16}$ Dyspnea and chest pain were the most common presenting complaint. ${ }^{17}$ The delayed phase is associated with transient herniation of viscera that could be absence or intermittent non specific symptoms. The obstruction phase is complication of a long standing herniation, manifesting as obstruction, strangulation and rupture.

Chest film, direct peritoneal lavage, fluoroscopy, upper Gl studies, ultrasound, CT scan, MRI, Liver-spleen scintigraphy, peritoneo-scintigraphic establish the diagnosis, however, lack both sensitivity and specificity. ${ }^{18}$

Chest film is basic screening for thoracoabdominal injury. The specific radiographic signs of blunt diaphragmatic rupture include intrathoracic location of abdominal viscera, with or without a site of focal constriction (collar sign) and clear demonstration of a nasogastric tube tip above the left hemidiaphragm. ${ }^{19}$ Chest film at the time of admission may be diagnostic traumatic diaphragmatic injury, 27 to $62 \%$ of left side injury and $33 \%$ of right side injury. ${ }^{9}$ So, chest film obtained at admission and repeated soon after are more valuable in suggestive the diagnosis of rupture of the diaphragm, especially left-sided injury. ${ }^{20}$

Ultrasound uses for evaluation of the blunt traumatic patient. It can be performed bed side and can suggest diaphragmatic rupture during FAST examination. $^{21}$ However, diagnosis of diaphragmatic hernia by ultrasound is difficult because of gasfilled intestinal loops, aerate lungs and acoustic shadowing from the rips. ${ }^{1}$

Barium studies are also used for diagnosis of traumatic diaphragmatic injury in non-acute setting, 
to confirm herniation of stomach and intestine. ${ }^{13,22}$

$\mathrm{CT}$ is the imaging modality of choice in severe blunt abdominal trauma and has a sensitivity of $61-71 \%$ and a specificity of $87-100 \%$ for diagnosis of acute traumatic diaphragmatic rupture. ${ }^{23}$ The multidetector CT with multiplanar reformatted images improves sensitivity and specificity of diagnosis. CT sign of diaphragmatic rupture can divide to direct sign and indirect sign. The direct signs are segmental diaphragmatic defect, dangling sign and absent diaphragm. ${ }^{5}$ The indirect signs related to herniation and loss of border between thorax and abdomen are herniation through a defect, hump sign, band sign, dependent viscera sign, sinus cutoff sign, abdominal content peripheral to the diaphragm or lung, elevated abdominal organs, abdominal fluid abutting a thoracic structure, abdominal viscera abutting thoracic fluid or a thorax organ, pneumothorax and pneumoperitoneum, hemothorax and hemoperitoneum.

$\mathrm{MRI}$ is not suitable in most acute traumatic cases, however, it may use in selected traumatic diaphragmatic hernia patients, especially in chronic complicated cases. ${ }^{1} \mathrm{MRI}$ imaging with multiplanar capability will clearly reveal the normal diaphragm and the hernia orifice as a diaphragmatic discontinuity on sagittal and coronal images.

The traditional method of treating blunt traumatic diaphragmatic injuries is open surgical repair. ${ }^{14}$ Acute left-sided traumatic diaphragmatic rupture is best approached through abdomen, although the chest approach adding laparotomy should be performed when necessary. Acute right -sided and chronic traumatic diaphragmatic rupture should be approached through the chest. ${ }^{24}$

The mortality rate in blunt diaphragmatic rupture vary from $7-42 \%$, associated with concurrent injuries rather than the diaphragm rupture itself. ${ }^{6,25}$ Mortality factors are age, high injury severity score, shock and bilateral diaphragmatic injury. ${ }^{6,16}$

\section{Conclusion}

Blunt traumatic diaphragmatic rupture can present with associated injuries. In cases of blunt thoracoabdominal injury, delayed clinical presentation of chest pain should be re-evaluated. Chest film is a basic imaging modality and can be used to make a diagnosis in these cases. A CT was performed to confirm diagnosis and showed associated splenic injury. However, it should be remembered that there is a high suspicious index of diaphragmatic injury in cases of thoracoabdominal trauma.

\section{References}

1. Eren S, Kantarci M, Okur A. Imaging of diaphragmatic rupture after trauma. Clin rad 2006; 61:467-77.

2. Sandstorm CK, Stern EJ. Diaphragmatic Hernias: A Spectrum of Radiographic Appearances. Curr Probl Diagn Radiol 2011;40:95-115.

3. Wardi G, Lasoff D, Cobb A, Hayden S. Traumatic diaphragmatic hernia. J Emerg Med 2014;46:80-2.

4. Eckstein M, Henderson SO. Thoracic trauma. In: Marx j. Robert H. Walls R. et. Al., eds. Rosen's emergency medicine: concepts and clinical practice. Philadelphia: Mosby Elsevier;2009; 387-413.

5. Desir A, Ghaye B. CT of Blunt Diaphragmatic Rupture. RadioGraphics 2012;32;477-98.

6. Kuo I, Liao C, Hsin M. Kang S, et al. Blunt diaphragmatic rupture - a rare but challenging entity in thoracolabdominal trauma. Am J Emerg Med 2012;30:919-24.

7. Meyers BF, McCabe CJ. Traumatic Diaphragmatic Hernia Occult Marker of Serious Injury. Ann Surg 1993:218(6):78390.

8. Al-Refaiea RE, Awad E, Mokbel EM. Blunt traumatic diaphragmatic rupture: a retrospective observational 
study of 46 patients. Interact Cardiovasc Thorac Surg 2009:9:45-9.

9. Killeen KL, Shanmuganathan K, and Mirvis SE. Imaging of Traumatic Diaphragmatic Injures. Seminars in Ultrasound, CT and MRI 2002;23:184-92.

10. Wiencek RG, Wilsong R, Steiger Z. Acute injuries of the diaphragm: an analysis of 165 cases. J Thorac CardiovascSurg 1986;92(6)989-93.

11. Kerney PA, Rouhhana SW, Burney RE. Blunt rupture of the diaphragm: Mechanism, diagnosis, and treatment. Ann Emerg Med 1989;18:1326-30.

12. Heiberg E, Wolverson MK, Hurd RN, Jagannadharo, et. al. CT recongnition of traumatic rupture of the diaphragm. AJR 1980;135:369-72.

13. Simpson J, Lobo DN, Shah AB, Rowlands BJ. Traumatic diaphragmatic rupture: associated injuries and outcome. Ann R Coll Surg Engl 2000;82:97-100.

14. Bosanquet D, Farboud A, LuckraZ H. A review diaphragmatic injury. Respiratory medicine CME 2009;2:1-6.

15. Rashid F, Chakrabarty MM, Singh R, Iftikhar SY. A review on delayed presentation of diaphragmatic rupture. World Journal of Emergency Surgery 2009;4:32.

16. Soundappan SV, Holland AJ, Cass DT, Farrow GB. Blunt traumatic diaphragmatic injuries in children. Injury, Int. J. Care Injured 2005;36:51-4.

17. Peer SM, Devaraddeppa PM, Buggi S. Traumatic diaphragmatic hernia-our experience. Inter J Surg 2009;7: 547-9.
18. Athanassiadi $\mathrm{K}$, Kalavrouziotis $\mathrm{G}$, Athannassiou M, Vernikos $\mathrm{P}$, et al. Blunt diaphragmatic rupture. Eur J cardio Thorac Sur 1999;15:469-74.

19. Sliker CW. Imaging of diaphragm injuries. Radiol clin N Am 2006;44:199-211.

20. Gelman R., Mirvis SE, Gens D. Diaphragmatic rupture due to blunt trauma: sensitivity of plain radiograph. AJR 1991;156:51-7.

21. Blaivas M, Brannam L, Hawkins M, Lyon M, et al,. Bedside emergency ultrasonographic diagnosis of diaphragmatic rupture in blunt abdominal trauma; Am J Emerg Med 2004;22:601-4.

22. Shackleton KL, Stewart ET, Taylor AJ. Traumatic diaphragmatic injuries: Spectrum of radiographic indings. RadioGraphics 1998;18:49-59.

23. Bergin D, Ennis R, Keogh C, Fenlon HM, et al,. The dependent viscera sign in CT diagnosis of blunt traumatic diaphragmatic rupture. AJR 2001;177:1137-40.

24. Haciibrahimoglu G, Solak O, Olcmen A, Bedirhan MA, et al,. Management of Traumatic Diaphragmatic Rupture. Surg Today 2004;34:111-4.

25. Bergeron E, Clas D, Ratte S, Beauchamp G, et al,. Impact of deferred treatment of blunt diaphragmatic rupture: A 15-Year experience in six trauma centers in Quebec. J Trauma Inj Infect Crit Care 2002:52(4):633-40. 